\title{
Root-like enamel pearl: a case report
}

\author{
Xiao-quan Mao
}

\begin{abstract}
Introduction: In general, enamel pearls are found in maxillary molars as a small globule of enamel. However, this case report describes an enamel pearl with a prolate spheroid shape which is $1.8 \mathrm{~mm}$ wide and $8 \mathrm{~mm}$ long. The different type of enamel pearl found in my clinic has significantly improved our understanding of enamel pearl etiology and pathophysiology.
\end{abstract}

Case presentation: A 42-year-old Han Chinese woman with severe toothache received treatment in my Department of Endodontics. She had no significant past medical history. A dental examination revealed extensive distal decay in her left mandibular first molar, tenderness to percussion and palpation of the periradicular zone, and found a deep periodontal pocket on the buccal lateral. Vitality testing was negative. Periapical radiographic images revealed radiolucency around the mesial apex. Cone beam computed tomography detected an opaque enamel pearl in the furcation area with a prolate spheroid shape of $1.8 \mathrm{~mm}$ wide and $8 \mathrm{~mm}$ long.

Conclusion: The enamel pearl described in this case report is like a very long dental root. Cone beam computed tomography may be used for evaluating enamel pearls.

Keywords: Cone beam computed tomography, Enamel pearl, Periapical radiographic images

\section{Introduction}

Enamel pearls are ectopic deposits of enamel which are located at the furcation area and near the cemento-enamel junction. In general, they are most commonly observed in molars, in particular maxillary molars. They appear as small globules of enamel firmly adherent to the tooth's root surface and as well-defined radio-opaque nodules. Internal enamel pearls present as well-defined circular areas of radiodensity extending from the enamel-dentin junction to the underlying coronal dentin.

\section{Case presentation}

A 42-year-old Han Chinese woman with severe toothache received treatment in my Department of Endodontics. A dental examination revealed extensive distal decay in her left mandibular first molar, tenderness to percussion and palpation of the periradicular zone, and found a deep periodontal pocket on the buccal lateral. Vitality testing was negative. Periapical radiographic images revealed radiolucency around the mesial apex. Cone beam computed tomography (CBCT) detected an opaque enamel pearl in

Correspondence: horse.m@163.com

Department of Endodontics, Stomatological Center, Affiliate Haikou Hospital, Xiangya Medical School, Central South University, Haikou 570208, Hainan, P.R. China

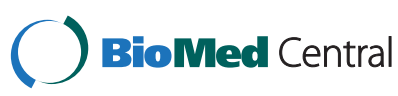

the furcation area with a prolate spheroid shape of $1.8 \mathrm{~mm}$ wide and $8 \mathrm{~mm}$ long (Figures 1, 2, and 3).

The tooth was diagnosed with symptomatic apical periodontitis with necrotic pulp. After Scandonest ${ }^{\oplus}$ (mepivacaine hydrochloride; Septodont, Inc.) was administered, her tooth was isolated using a rubber dam. As usual, in the initial access cavity, three orifices were found. In addition, a root-like image was found on periapical imaging (Figure 4). Therefore the access cavity was further prepared into a square shape; however, no orifice was found after meticulous exploration of the pulp chamber floor with a hand K-file.

Three canals were instrumented with stainless-steel hand $\mathrm{K}$-files accompanied by X-Smart ${ }^{\mathrm{TM}}$ Motor (Dentsply, USA) rotary instrumentation using a crown-down technique. Her root canals were irrigated with sodium hypochlorite $5.25 \%$ and dried completely. Camphor phenol was placed as an intracanal dressing. Then, the access cavity was sealed temporarily with zinc oxide.

One week later, she was completely asymptomatic. Her root canals were obturated with gutta-percha (Dentsply, USA) after the working length was radiographically confirmed with gutta-percha. 


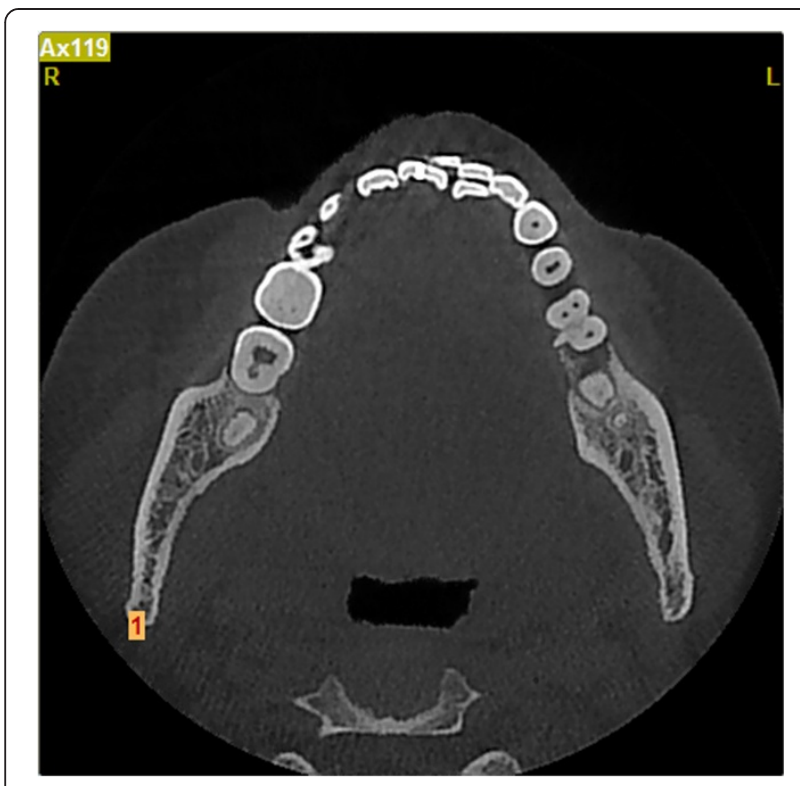

Figure 1 Enamel pearl in furcation area.

Subsequently, she was referred to the restorative department for final restoration. Three months later, she had no symptoms.

\section{Discussion}

Enamel pearls are anomalies of enamel on primary and permanent teeth roots that usually appear at furcation areas, especially in maxillary second and third molars [1]. They usually occur as solitary lesions, but two to four enamel pearls have been observed on the same tooth [2]. The prevalence of enamel pearls has been reported to vary

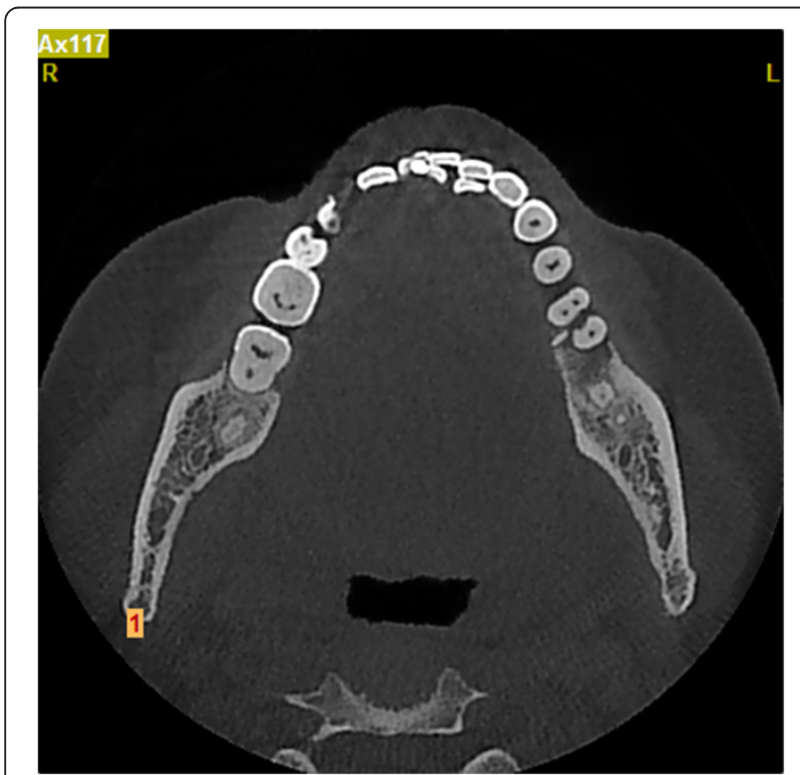

Figure 2 Computed tomography horizontal section view.

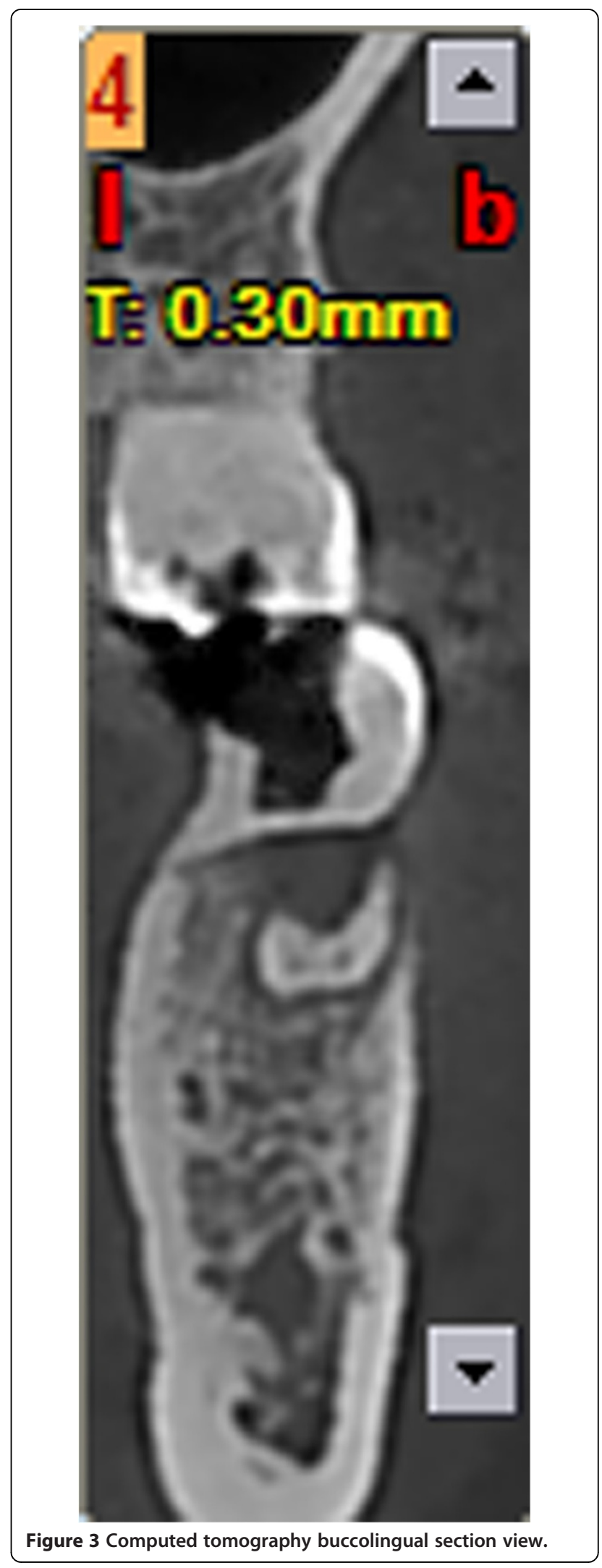

Figure 3 Computed tomography buccolingual section view. 


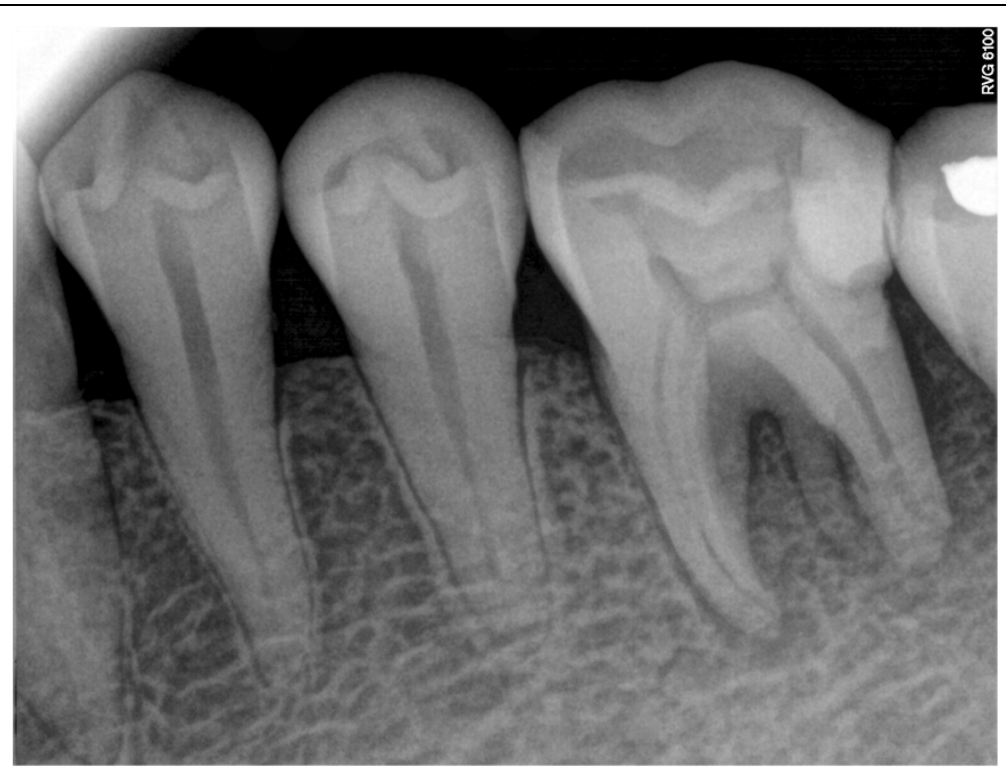

Figure 4 Root-like enamel pearl.

between 1.1 and 9.7\% [3]. Enamel pearls are not common in teeth with a single root, although there are rare reports of them occurring on the roots of premolars, canines and incisors [4-6]. It is generally accepted that enamel pearls are usually found adherent to the external root surface of the tooth, but on rare occasions they may be detected within the dentin [7]. They vary in size, ranging from $0.3 \mathrm{~mm}$ to $4 \mathrm{~mm}$ in diameter [8]. But in this case report, the enamel pearl in our patient was unusually large, $1.8 \mathrm{~mm}$ wide and $8 \mathrm{~mm}$ long.

Three types of enamel pearls have been described $[9,10]$ : (1) true enamel pearls, consisting entirely of enamel; (2) composite enamel pearls, or enamel-dentin pearls, containing a core of tubular dentin; and (3) enamel-dentinpulp pearls, containing a pulp horn, probably extending from the coronal pulp chamber or root canal.

The etiology of enamel pearls remains obscure. The most widely accepted theory is that enamel pearls develop as a result of localized developmental activity of a remnant of Hertwig's epithelial root sheath which maintains its potential for enamel formation, which could explain how this structure has remained adherent to the root surface during root development $[11,12]$. It is believed that these cells differentiate into functioning ameloblasts and produce enamel deposits on the root.

CBCT may be helpful to find enamel pearls [13-15]. Enamel pearls are anatomical structures that can lead to clinical implications if associated with the retention of plaque [16] which could prevent periodontal attachment and predispose the area to pocket formation and periodontal disease [17]. In this case, the enamel pearl did not develop tubular dentin and pulp; it is only composed of enamel. Because enamel pearls may contain tubular dentin and/or a pulp chamber, meticulous exploration of the developmental groove in the pulp chamber floor is suggested in order to locate the orifices of canals. Moreover, any dentin projection that could cover an existing orifice should be removed carefully when dental pulp disease is treated.

\section{Conclusions}

The enamel pearl described in this case report is like a very long dental root. In order to ensure the root canal is not missed, the orifice in the pulp chamber floor must be carefully explored. In addition, tubular dentin within enamel pearls should be evaluated using $\mathrm{CBCT}$ when these teeth need to be treated.

\section{Consent}

Written informed consent was obtained from the patient for publication of this case report and any accompanying images. A copy of the written consent is available for review by the Editor-in-Chief of this journal.

\section{Abbreviations}

CBCT: Cone beam computed tomography.

\section{Competing interests}

The author declares that he has no competing interests.

\section{Acknowledgements}

I would like to thank Professor Pu Xu and Xin-chun Jian who modified the manuscript, Min-xin Mao and Dr. Tim who edited its grammar.

Received: 5 February 2014 Accepted: 24 May 2014

Published: 9 July 2014 
References

1. Shojaeian S, Ghoddusi J, Hajian S: A case report of maxillary second molar with two palatal root canals and a furcal enamel pearl. Iran Endod J 2013, 8(1):37-39.

2. Wu li: A case report of right maxillary third molar with multiple enamel pearls. J Pract Stomatol 2013, 29(4):510.

3. Chrcanovic BR, Abreu MH, Custódio AL: Prevalence of enamel pearls in teeth from a human teeth bank. J Oral Sci 2010, 52(2):257-260.

4. Sehic A, Risnes S, Khan QE, Khuu C, Osmundsen H: Gene expression and dental enamel structure in developing mouse incisor. Eur J Oral Sci 2010, 118(2):118-130.

5. Sehic A, Peterkova R, Lesot $H$, Risnes S: Distribution and structure of the initial dental enamel formed in incisors of young wild-type and Tabby mice. Eur J Oral Sci 2009, 117(6):644-654.

6. Sehic A, Peterkova R, Lesot $H$, Risnes S: P32-distribution and structure of the initial dental enamel formed in incisors of young wild-type and Tabby mice. Bull Group Int Rech Sci Stomatol Odontol 2011, 49(3):104-106.

7. Sehic A, Nirvani M, Risnes S: Incremental lines in mouse molar enamel. Arch Oral Biol 2013, 58(10):1443-1449.

8. Versiani MA, Cristescu RC, Saquy PC, Pécora JD, de Sousa-Neto MD: Ename pearls in permanent dentition: case report and micro-CT evaluation. Dentomaxillofac Radiol 2013, 42(6):20120332.

9. Cavanha AO: Curitiba, Paraná. Enamel pearls. Oral Surg Oral Med Oral Pathol 1965, 19:373-382.

10. Saini T, Ogunleye A, Levering N, Norton NS, Edwards P: Multiple enamel pearls in two siblings detected by volumetric computed tomography. Dentomaxillofac Radiol 2008, 37(4):240-244.

11. Khan QE, Sehic A, Khuu C, Risnes S, Osmundsen H: Expression of Clu and Tgfb1 during murine tooth development: effects of in-vivo transfection with anti-miR-214. Eur J Oral Sci 2013, 121(4):303-312.

12. Khan QE, Press CM, Sehic A, Landin MA, Risnes S, Osmundsen H: Expression of prion gene and presence of prion protein during development of mouse molar tooth germ. Eur J Oral Sci 2010, 118(6):559-565.

13. Akgül N, Caglayan F, Durna N, Sümbüllü MA, Akgül HM, Durna D: Evaluation of enamel pearls by cone-beam computed tomography (CBCT). Med Oral Patol Oral Cir Bucal 2012, 17(2):e218-e222.

14. Kottoor J, Hemamalathi S, Sudha R, Velmurugan N: Maxillary second molar with 5 roots and 5 canals evaluated using cone beam computerized tomography: a case report. Oral Surg Oral Med Oral Pathol Oral Radiol Endod 2010, 109(2):e162-e165.

15. Aggarwal V, Singla M, Logani A, Shah N: Endodontic management of a maxillary first molar with two palatal canals with the aid of spiral computed tomography: a case report. J Endod 2009, 35(1):137-139.

16. Tabari ZA, Kadkhodazadeh M, Khademi M: Enamel pearl as a predisposing factor to localized severe attachment loss: a case report. Res J Med SCi 2011, 5(3):141-144.

17. Romeo U, Palaia G, Botti R, Nardi A, Del Vecchio A, Tenore G, Polimeni A: Enamel pearls as a predisposing factor to localized periodontitis. Quintessence Int 2011, 42(1):69-71.

\section{Submit your next manuscript to BioMed Central and take full advantage of:}

- Convenient online submission

- Thorough peer review

- No space constraints or color figure charges

- Immediate publication on acceptance

- Inclusion in PubMed, CAS, Scopus and Google Scholar

- Research which is freely available for redistribution

Submit your manuscript at www.biomedcentral.com/submit
C Biomed Central 